\title{
PAMPA CORTE - UM MODELO DE SIMULAÇÃO PARA O CRESCIMENTO E ENGORDA DE GADO DE CORTE ${ }^{1}$
}

\author{
PAMPA CORTE - A MODEL THAT SIMULATES BEEF CATTLE \\ GROWING AND FATTENING PROCESS
}

\author{
Vicente Celestino Pires Silveira ${ }^{2}$
}

- REVISÃO BIBLIOGRÁFICA -

RESUMO

Modelos de simulação são ferramentas que podem ser usadas para reduzir o tempo e o custo da experimentação de campo. O modelo PAMPA CORTE foi desenvolvido com a finalidade de simular o desenvolvimento corporal de bovinos de corte de uma maneira dinâmica e mecanística. Para simular o desempenho animal individual, são considerados dois submodelos. O primeiro, simula a ingestão e a digestão do alimento $e$ prediz as produções diárias da quantidade de energia $e$ proteína metabólica. $O$ segundo considera estas produções e simula as mudanças de peso vivo do animal. Neste trabalho, os resultados simulados pelo modelo são comparados com os dados reais de ganho de peso obtidos por novilhos suplementados, do pós-desmame ao abate com 14 meses de idade. Foram feitas três simulações para comparar os dados reais com os dados simulados. Os resultados simulados pelo PAMPA CORTE apresentaram uma ótima performance na simulação do ganho de peso de machos mestiços Hereford X Nelore, suplementados em campo nativo.

Palavras-chave: sistema computacional, bovinos de corte, modelo de digestão, ganho de peso.

\section{SUMMARY}

Simulation Models are tools that can be used to reduce time and cost of field experimentation. The PAMPA CORTE model was developed to simulate the growing beef cattle in a dynamic and mechanistic way. Two individual animal submodels are considered. The first simulates the ingestion and digestion of food and predicts the daily productions of the amount of metabolic energy and digestible protein. The second considers these productions to simulate the changes of live weight of the animal. In this research, the results of the simulations from the model were compared with the data obtained from the field experiment. The Hereford $x$ Nelore crossbreed was supplemented from after weaning to slaughtering at 14 months old. Three simulations were made to compare the real data with the simulated data from the model. The simulation results from the PAMPA CORTE model showed a great performance in the simulation of the gaining of crossbred males supplemented in natural pasture.

Key words: computer system, beef cattle, digestion model, live weight gain.

\section{INTRODUÇÃO}

O apoio tecnológico é necessário para incrementar a produção nos complexos sistemas agropecuários. Porém, a pesquisa física tradicional, baseada na experimentação de campo, está sendo cada vez mais questionada, particularmente em locais caracterizados por variabilidade climática. Diferenças entre tratamentos só podem ser pertinentes para o ano e as condições específicas do experimento. Outras circunstâncias podem negar ou mesmo inverter prioridades de tratamentos. Repetição durante anos só amplia o custo sem necessariamente melhorar a informação obtida.

\footnotetext{
${ }^{1}$ Parte da tese de PhD., defendida na Universidade de Edimburgo - Escócia.

${ }^{2}$ Pesquisador EMBRAPA, CPPSUL, CP 242, CEP 96400-970, Bagé, RS, Brasil. Email: vicente@ cppsul.embrapa.br. Recebido para publicação em 17.04.01. Aprovado em 19.09.01
} 
Além disto, resulta em demoras inaceitáveis pelos usuários finais (DENT, 1996).

O uso de modelos de simulação é uma ferramenta útil para redução do tempo e do custo da experimentação de campo. Os modelos são classificados como empíricos ou mecanisticos. Modelos mecanisticos requerem que os processos simulados tenham uma base física ou fisiológica, enquanto modelos empíricos consistem em funções que são escolhidas arbitrariamente para ajustar medidas de campo ou laboratório (MONTEITH, 1996). Modelos empíricos são então local específico e não transferível para zonas agro-ecológicas (DENT et al., 1994). Modelos mecanisticos, devido ao seu principio, podem ser transferíveis e pode ser usados para explorar uma gama extensiva de tratamentos em locais diferentes que seriam impossível com experimentação de campo, devido ao custo e tempo requerido. Estes são importantes ferramentas que permitem a integração dos dados obtidos em experimentos e em estudos de laboratório pertinentes a um sistema. Este é um modo importante para ajudar a compreender os sistemas reais nos quais é requerida uma visão holística (BECK \& DENT, 1987; DENT \& THORNTON, 1988).

Revisões sobre modelos desenvolvidos para simular rebanhos e sistemas pastoris são amplamente encontrados na literatura (HERRERO $\boldsymbol{e} t$ al., 1998; DENT et al., 1994; MACNEIL et al., 1985; HANSON et al., 1985; CHUDLEIGH \& CEZAR, 1982).

O objetivo deste trabalho foi descrever o modelo PAMPA CORTE e demonstrar algumas simulações realizadas com o modelo, comparandoas com os dados reais de ganho de peso obtidos por novilhos suplementados do pós-desmame ao abate, com 14 meses de idade.

\section{DESCRIÇÃO GERAL DO MODELO}

O modelo PAMPA CORTE foi desenvolvido com a finalidade de simular o desenvolvimento corporal de bovinos de corte de uma maneira mecanistica e dinâmica, por meio do uso de equações diferencias integrais. Para simular o desempenho animal individual, foram considerados dois sub-modelos. O primeiro sub-modelo simulou a ingestão e a digestão do alimento e prediz as produções diárias da quantidade de energia e proteína metabólica disponível para a produção. $\mathrm{O}$ segundo considerou estas produções e prediz as mudanças de peso vivo do animal.

O software SB-ModelMaker, version 3.0.3 (Zeton Tech, Nottingham, UK) foi utilizado no desenvolvimento deste aplicativo. Na figura 1, pode ser observada a estrutura geral do modelo considerando o nível de animal e de rebanho.

Para a simulação de um rebanho, o modelo assume que cada grupo de animais tem uma distribuição normal com $68 \%$ de animais entre a média e um desvio padrão, $27 \%$ entre 2 e 3 desviospadrão e o restante mais que 3 desvios padrões (ANDERSON et al., 1994). Conseqüentemente, cinco pontos na curva de distribuição normal foram escolhidos como "pontos de simulação" (Figura 1) que são extrapolados para os animais sob influência deste ponto. O número mínimo de animais no rebanho para que três pontos de simulação sejam preenchidos é oito. Porém, os cinco pontos de simulação são simulados quando o rebanho tiver no mínimo 34 animais. Este enfoque visa reduzir o tempo de uso do processador da máquina e a redução do espaço em disco tornando mais eficiente $\mathrm{o}$ processo. Portanto, independentemente se o rebanho contém 50 ou 500 animais, o tempo de processamento e espaço físico ocupado na máquina será o mesmo.

Para simular o desempenho animal individual foram considerados duas etapas. A primeira simula a ingestão e a digestão do alimento, e a segunda prediz as mudanças de peso vivo do animais. Os sub-modelos de ingestão e digestão estão baseados no modelo descrito por HERRERO (1997), o qual tem como base os modelos de ILLIUS \& GORDON (1991) e SNIFFEN $\boldsymbol{e t}$ al., (1992). Este usa um time-step de uma hora. A ingestão diária do alimento pelo animal é obtida como a soma de refeições individuais simuladas para cada 24 horas. Para esta simulação, a capacidade máxima de rúmen é considerada. A refeição acontece quando o conteúdo de matéria seca (MS) do rúmen é menor que $70 \%$ de capacidade (ILLIUS \& GORDON ,1991). A maneira na qual o conteúdo de MS do rúmen é obtido e as variáveis associadas com os processos de digestão pode ser encontrado em ILLIUS \& GORDON (1991) e HERRERO (1998). Estes modelos consideram somente restrições físicas ao consumo. Isto é aceitável em nosso caso, porque a meta principal é simular desempenho animal em sistemas pastoris, em que a dieta está basicamente composta por forragens e a proporção de concentrado é baixo. Por conseguinte, é esperado que a digestibilidade da MS esteja abaixo do ponto de restrição metabólica (VAN SOEST, 1994). Porém, em situações onde ocorre restrição metabólica de consumo, modelos que consideram este fator podem ser incorporados, por exemplo, ILLIUS \& JESSOP (1996). Entretanto, fatores ambientais e efeitos da oferta de alimentos precisam ser considerados na simulação de sistemas pastoris, por exercerem grande influência na performance animal. 


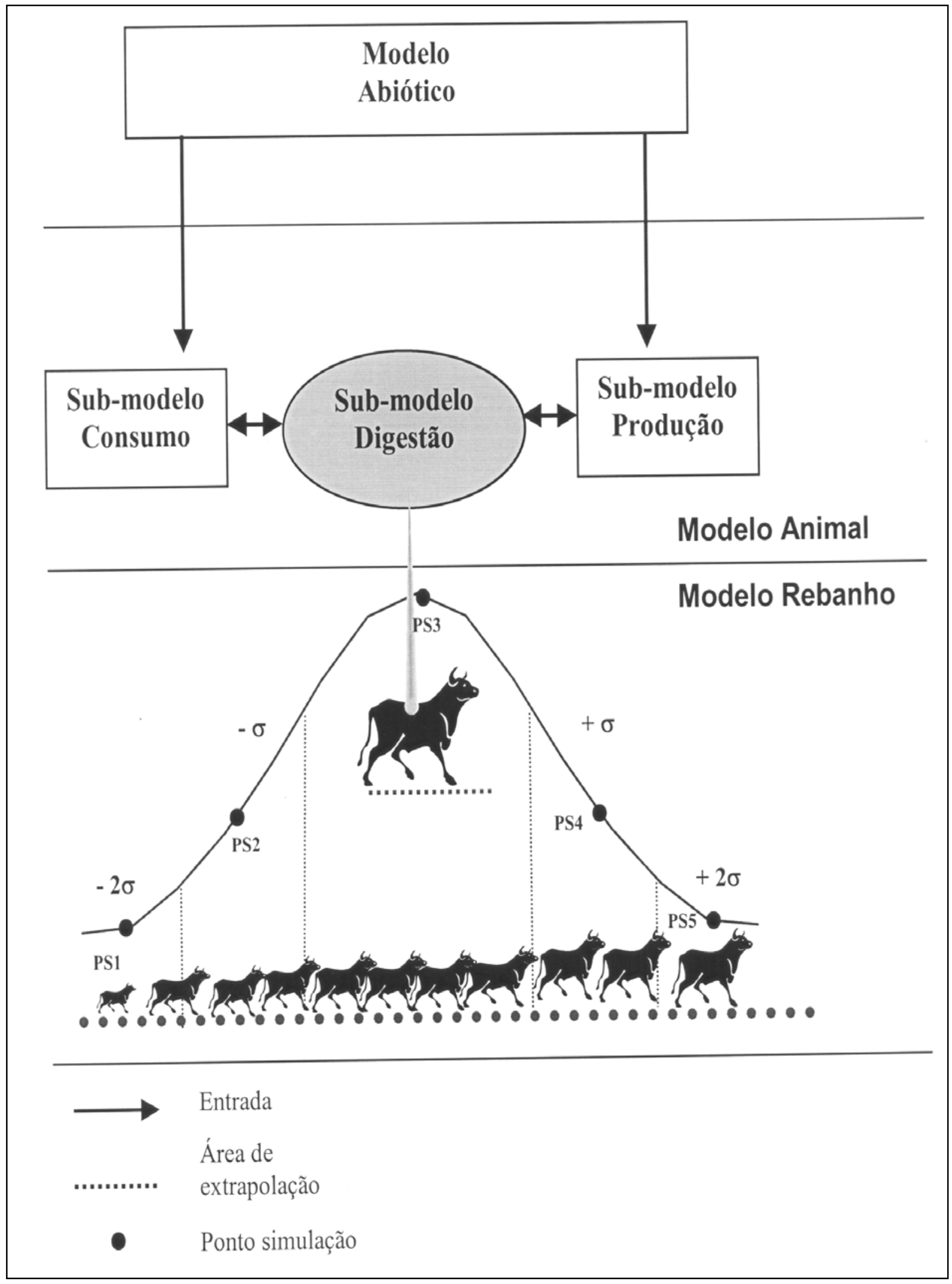

Figura 1 - Diagrama do modelo animal. 
Para simular os efeitos ambientais, a revisão feita pelo NRC (1981) sobre o efeito dos mesmos no consumo de alimentos por animais domésticos foi considerada. $\mathrm{O}$ efeito de temperatura é considerado quando esta estiver fora da faixa de conforto $\left(15\right.$ a $\left.25^{\circ} \mathrm{C}\right)$. Temperaturas acima de $25^{\circ} \mathrm{C}$ reduzem o consumo dos animais. CSIRO (1990) considera $1 \%$ de redução para cada grau acima de $25^{\circ} \mathrm{C}$. Esta mesma suposição é assumida no modelo. Temperaturas abaixo de $15^{\circ} \mathrm{C}$ sem chuva estimulam o consumo do animal. NRC (1981) estima estas variações entre 2 e $5 \%$ para temperaturas de 5 a $15^{\circ} \mathrm{C}$ e aumentos de até $10 \% \mathrm{a}-15^{\circ} \mathrm{C}$. Considerando este fato, o modelo simula aumentos de consumo de $1 \%$ para cada $3^{\circ} \mathrm{C}$ quando a temperatura é menor do que $15^{\circ} \mathrm{C}$. Porém, baixas temperaturas associadas com chuva causam uma depressão de 10 a $30 \%$ no consumo (NRC, 1981). O efeito da baixa temperatura associada à chuva também é considerado no modelo. Neste caso o consumo é reduzido em $1 \%$ para cada grau abaixo de $15^{\circ} \mathrm{C}$, em dias chuvosos.

A disponibilidade de forragem é outra restrição importante no consumo em sistemas pastoris. A aproximação da relação entre disponibilidade (abaixo de $1200 \mathrm{~kg} / \mathrm{MS}$ ) e consumo adotada pelo NRC (1996) é utilizada no modelo.

O modelo de produção, que simula os processos de crescimento e engorda em bovinos de corte, foi desenvolvido considerando modelos e dados do ARC (1980), AFRC (1993), CSIRO (1990) e NRC (1996). Para simular condições de animais em regime de pastejo, o modelo deve considerar os diferentes níveis de energia e proteína a que os animais podem ser submetidos diariamente, durante o crescimento e a engorda. Seis situações foram consideradas no modelo: a) fornecimento de energia e proteína inferior ao exigido para manutenção; b) fornecimento de proteína inferior ao exigido para manutenção; c) fornecimento de energia inferior ao exigido para manutenção; d) fornecimento de energia e proteína em equilíbrio ao exigido para manutenção; e) fornecimento de energia e proteína em equilíbrio ao exigido para manutenção, com proteína que limita o ganho máximo; f) fornecimento de energia e proteína em equilíbrio ao exigido para manutenção, com energia que limita o ganho máximo.

Para considerar a qual nível alimentar que o animal é submetido, o modelo de produção calcula a quantia de energia metabólica e proteína necessário para manutenção do mesmo. A quantidade de proteína metabólica, g/dia, e de energia, MJ/dia, exigido para manutenção é calculado considerando o peso vivo do animal, segundo o AFRC (1993).

\section{DESCRIÇÃO DOS DADOS UTILIZADOS NA COMPARAÇÃO COM OS SIMULADOS}

Após o desmame, com aproximadamente seis meses de idade, 12 machos castrados mestiços Hereford $x$ Nelore foram colocados num potreiro de campo nativo de 10 hectares. Os animais eram suplementados duas vezes ao dia, com um suplemento composto de farelo de arroz $( \pm 50 \%)$, resíduos agro-industriais resultante do processo de limpeza do arroz $( \pm 35 \%)$ e farelo de trigo, sorgo ou milho $( \pm 15 \%)$. Amostras da disponibilidade e qualidade da pastagem foram realizadas a cada 28 dias. Os animais foram pesados a cada 14 dias durante todo o período experimental. A quantidade do suplemento oferecida aos animais foi ajustada de acordo com a disponibilidade e qualidade de forragem e durante o ano, com a finalidade de abatelos aos 14 meses, com 380-400kg de peso vivo (Figura 2).

O concentrado foi fornecido aos animais em cocho, com área de 0,5m/por animal. Para simular a competição entre os animais pelo concentrado, fato que ocorre normalmente nesta situação, o modelo considera os seguintes ajustes por ponto de simulação (PS) (Figura 1). No PS1, assumiu-se que os animais comeram $80 \%$ da média do concentrado fornecido e os animais do PS2 $90 \%$. As mesmas suposições foram feitas para os animais acima da média. O modelo assume que aquele animais do PS4 e PS5 comeram respectivamente $110 \%$ e $120 \%$ da média do concentrado fornecido.

A variação da qualidade da pastagem e do suplemento durante o ano pode ser observada na tabela 1. As variações substanciais na disponibilidade e qualidade de pastagem natural entre os meses são claramente percebidas (SILVEIRA et al., 1998). A variação da qualidade no suplemento pode ser explicada principalmente graças à variação da composição dos resíduos oriundos dos processos agro-industriais do arroz utilizadas no suplemento oferecido (GONÇALVES \& SACCOL, 1995).

As tabelas 2 e 3 contêm os parâmetros utilizados no modelo para o campo nativo e o concentrado. Os parâmetros associados com a proteína da forragem: proporção de proteína solúvel da proteína total da forragem (aCPForage), proporção de proteína potencialmente degradável da proteína total da forragem (bCPForage), proporção de proteína não degradável da proteína total da forragem (uCPForage), foram obtidos do AFRC (1993), tabela 4.1, pg. 48, que contém os valores de 


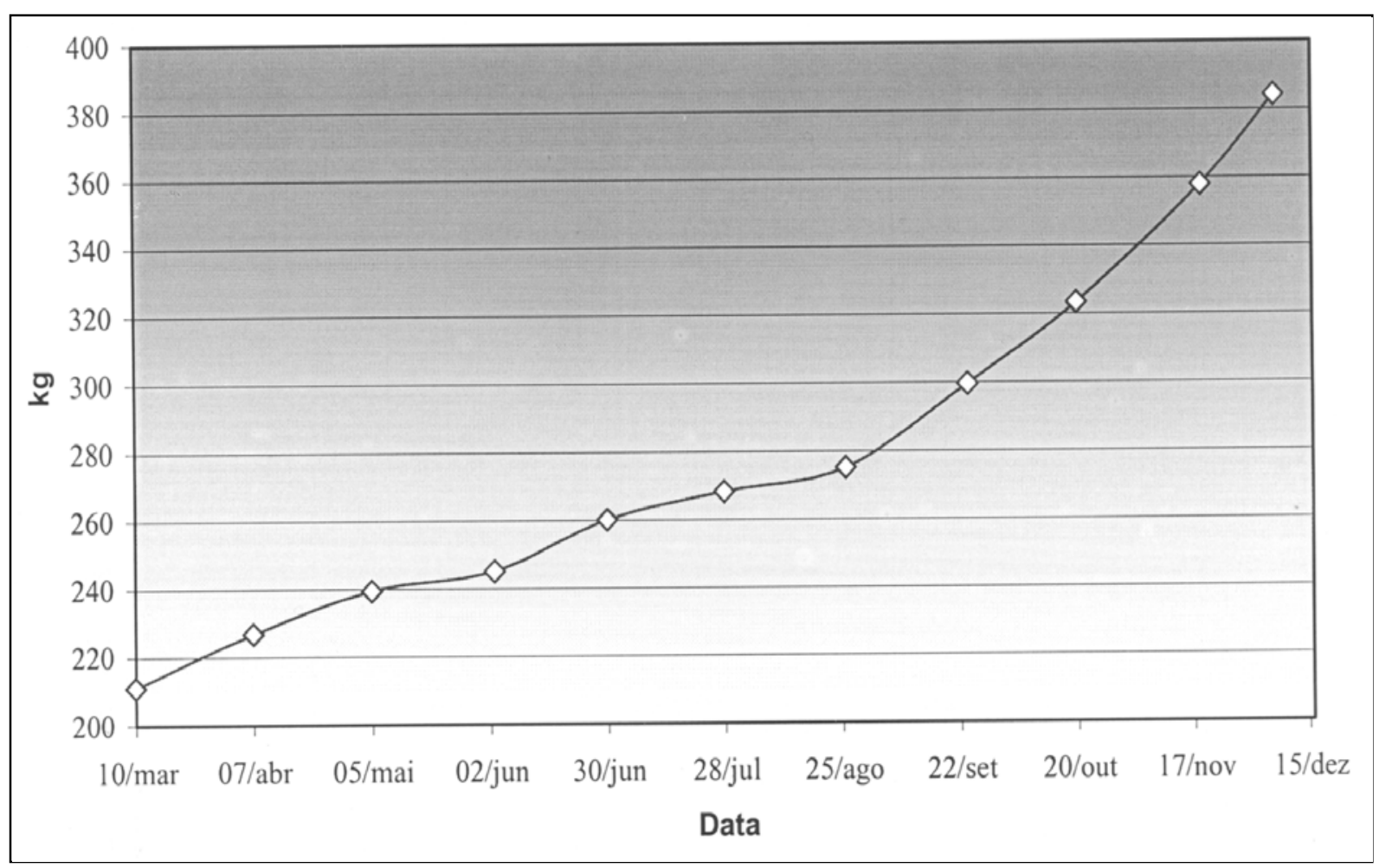

Figura 2 - Ganho de peso dos animais no período experimental.

Tabela 1 - Características nutricionais do campo nativo e do concentrado ofertado aos animais.

\begin{tabular}{|c|c|c|c|c|c|c|c|}
\hline \multirow{3}{*}{ Data } & PB & FDN & FDA & DIVMS & $\mathbf{E E}$ & $\mathbf{P}$ & Disponibilidade \\
\hline & \multicolumn{6}{|c|}{$\% \mathbf{D M}$} & $\mathrm{kg} / \mathrm{ha}$ \\
\hline & \multicolumn{7}{|c|}{ Campo Nativo } \\
\hline $10 / 03 / 93$ & 6,56 & 75,40 & 45,41 & 46,23 & $1,00^{*}$ & 0,08 & 976,00 \\
\hline $07 / 04 / 93$ & 5,19 & 76,20 & 41,17 & 55,28 & $1,00^{*}$ & 0,08 & 1304,00 \\
\hline $05 / 05 / 93$ & 4,94 & 76,30 & 46,50 & 42,40 & $1,00^{*}$ & 0,07 & 1638,00 \\
\hline $02 / 06 / 93$ & 7,81 & 76,10 & 45,89 & 40,77 & $1,00^{*}$ & 0,07 & 1840,00 \\
\hline $30 / 06 / 93$ & 6,81 & 75,40 & 44,63 & 39,10 & $1,00^{*}$ & 0,07 & 2180,00 \\
\hline $28 / 07 / 93$ & 6,63 & 78,80 & 46,88 & 38,96 & $1,00^{*}$ & 0,08 & 1571,00 \\
\hline $25 / 08 / 93$ & 7,88 & 78,10 & 41,58 & 32,75 & $1,00^{*}$ & 0,04 & 1130,00 \\
\hline $22 / 09 / 93$ & 7,81 & 75,50 & 49,36 & 29,23 & $1,00^{*}$ & 0,03 & 742,00 \\
\hline $20 / 10 / 93$ & 6,19 & 74,00 & 42,03 & 46,44 & $1,00^{*}$ & 0,05 & 1468,00 \\
\hline $17 / 11 / 93$ & 9,00 & 74,00 & 42,36 & 46,55 & $1,00^{*}$ & 0,07 & 963,00 \\
\hline \multirow[t]{2}{*}{$07 / 12 / 93$} & 10,50 & 74,90 & 42,90 & 45,63 & $1,00^{*}$ & 0,10 & 981,00 \\
\hline & & & Concentrad & & & & $\begin{array}{c}\text { Disponibili- } \\
\text { dade } \\
\text { kg/Cabeça }\end{array}$ \\
\hline $10 / 03 / 93$ & 18,31 & 37,40 & 18,62 & 59,04 & 10,87 & 1,32 & 2,00 \\
\hline $19 / 05 / 93$ & 19,88 & 37,40 & 16,88 & 61,86 & 11,00 & 1,40 & 2,50 \\
\hline $11 / 08 / 93$ & 18,66 & 37,40 & 14,79 & 69,95 & 9,09 & 1,36 & 3,00 \\
\hline $08 / 10 / 93$ & 20,06 & 37,40 & 15,43 & 67,00 & 9,05 & 1,34 & 3,00 \\
\hline
\end{tabular}

Proteína Bruta; FDN, Fibra em detergente neutro; FDA, Fibra em detergente Ácido; DIVMS, Digestibilidade in vitro da Matéria Seca; EE, Extrato Etéreo ; P, Fósforo.

* Valor assumido para pastagens. 
Tabela 2 - Parâmetros para o campo nativo utilizados no modelo.

\begin{tabular}{lccccc}
\hline Data & K2Forage & aCPForage & Parâmetros bCPForage & uCPForage & CCForage \\
\hline $10 / 03 / 93$ & 0,05 & 0,24 & 0,67 & 0,09 & 0,25 \\
$07 / 04 / 93$ & 0,05 & 0,24 & 0,67 & 0,09 & 0,28 \\
$05 / 05 / 93$ & 0,05 & 0,24 & 0,67 & 0,09 & 0,24 \\
$02 / 06 / 93$ & 0,04 & 0,24 & 0,67 & 0,09 & 0,24 \\
$30 / 06 / 93$ & 0,03 & 0,22 & 0,60 & 0,18 & 0,24 \\
$28 / 07 / 93$ & 0,03 & 0,22 & 0,60 & 0,18 & 0,25 \\
$25 / 08 / 93$ & 0,04 & 0,24 & 0,67 & 0,09 & 0,21 \\
$22 / 09 / 93$ & 0,05 & 0,24 & 0,67 & 0,09 & 0,22 \\
$20 / 10 / 93$ & 0,05 & 0,24 & 0,67 & 0,09 & 0,25 \\
$17 / 11 / 93$ & 0,05 & 0,24 & 0,67 & 0,09 & 0,24 \\
$07 / 12 / 93$ & 0,04 & 0,24 & 0,67 & 0,09 & 0,19 \\
\hline
\end{tabular}

K2Forage, Taxa de digestão da parede celular da forragem $\left(\mathrm{h}^{-1}\right)$; aCPForage, Proporção de proteína solúvel da proteína total da forragem; bCPForage, Proporção de proteína potencialmente degradável da proteína total da forragem; uCPForage, Proporção de proteína não degradável da proteína total da forragem; CCForage, Proporção de conteúdo celular da forragem; DCWForage, Proporção de parede celular potencialmente degradável da forragem.

Tabela 3 - Parâmetros para concentrados utilizados no modelo.

\begin{tabular}{|c|c|c|c|c|c|c|c|}
\hline Data & K2Concentrate & aCPConcentrate & bCPConcentrate & $\begin{array}{c}\text { Parâmetros } \\
\text { uCPConcentrate }\end{array}$ & Amido & DCWConcentrate & FatConcentrate \\
\hline $10 / 03 / 93$ & 0,07 & 0,36 & 0,55 & 0,09 & 0,75 & 0,18 & 108,70 \\
\hline $07 / 04 / 93$ & 0,07 & 0,36 & 0,55 & 0,09 & 0,75 & 0,18 & 108,70 \\
\hline $05 / 05 / 93$ & 0,07 & 0,36 & 0,55 & 0,09 & 0,75 & 0,18 & 108,70 \\
\hline $02 / 06 / 93$ & 0,07 & 0,36 & 0,55 & 0,09 & 0,75 & 0,24 & 110,00 \\
\hline $30 / 06 / 93$ & 0,07 & 0,36 & 0,55 & 0,09 & 0,75 & 0,24 & 110,00 \\
\hline 28/07/93 & 0,07 & 0,36 & 0,55 & 0,09 & 0,75 & 0,23 & 110,00 \\
\hline $25 / 08 / 93$ & 0,07 & 0,36 & 0,55 & 0,09 & 0,75 & 0,28 & 90,90 \\
\hline $22 / 09 / 93$ & 0,07 & 0,36 & 0,55 & 0,09 & 0,75 & 0,28 & 90,90 \\
\hline $20 / 10 / 93$ & 0,07 & 0,36 & 0,55 & 0,09 & 0,75 & 0,28 & 90,90 \\
\hline $17 / 11 / 93$ & 0,07 & 0,36 & 0,55 & 0,09 & 0,75 & 0,26 & 90,50 \\
\hline $07 / 12 / 93$ & 0,07 & 0,36 & 0,55 & 0,09 & 0,75 & 0,26 & 90,50 \\
\hline
\end{tabular}

K2Concentrate, Taxa de digestão da parede celular do concentrado $\left(\mathrm{h}^{-1}\right)$; aCPConcentrate, Proporção de proteína solúvel da proteína total do concentrado; bCPConcentrate, Proporção de proteína potencialmente degradável da proteína total do concentrado; uCPConcentrate, Proporção de proteína não degradável da proteína total do concentrado; Amido, Proporção de amido presente no carbohidrato não estrutural (NSC); DCWConcentrate, Proporção de parede celular potencialmente degradável do concentrado; FatConcentrate, quantidade de gordura presente no concentrado $(\mathrm{g} / \mathrm{kg})$.

N degradável por classe de alimento. Os valores associados com a proteína do concentrado foram obtidos do mesmo modo. Os valores assumidos para o campo nativo na maior parte do ano foram aqueles citados para forragem verde. No entanto, durante o inverno, foram utilizados os valores para feno devido às características do mesmo nos meses de inverno.

O conteúdo celular da forragem (CCForage) pode ser considerado inteiramente ou largamente digerível (VAN SOEST, 1994). Para o cálculo de CCForage, foi considerada a diferença entre a matéria seca total (MS) e a quantidade de fibra em detergente neutro (FDN). Para calcular a porção digerível da parede celular da forragem (DCWForage), a digestibilidade in vitro (DIVMS) e CCForage foram consideradas. Portanto, o
DCWForage foi calculado pelo DIVMS subtraído o valor de CCForage e a fração de proteína, que é simulada separadamente, conforme citado no parágrafo anterior.

A taxa de digestão da parede celular diminui com a maturidade da planta (ILLIUS \& GORDON, 1991; NRC, 1996; DOANE et al., 1997; COBLENTZ et al., 1998). ILLIUS \& GORDON (1991) encontraram taxas para Dactylis glomerata de $0.128 \mathrm{~h}^{-1}$ na fase vegetativa e de $0.046 \mathrm{~h}^{-1}$ na fase madura. COBLENTZ et al. (1998) compararam quatro estágios fisiológicos para o campo nativo no Kansas, EUA, e encontraram taxas de digestão que variaram de $0.056 \mathrm{~h}^{-1}$ no estágio vegetativo até $0.032 \mathrm{~h}^{-1}$ na maturidade. No modelo, o valor para a taxa de digestão da parede celular (K2Forage) 
considera o estágio fisiológico da pastagem natural, com um valor mínimo durante inverno e valor máximo durante outono e primavera.

DE PETERS et al. (1997) citam valores de $0.07 \mathrm{~h}^{-1}$ para a taxa de digestão da parede celular em farelo de arroz, enquanto NRC (1996) fornece valores de $0.08 \mathrm{~h}^{-1}$. A taxa de degradação citadas para milho, sorgo e arroz variam de $0.05 \mathrm{~h}^{-1}$ à $0.08 \mathrm{~h}^{-1}$ (SNIFFEN et al., 1992; KRISHNAMORTHY et al., 1995; NRC, 1996). No modelo, um valor de $0.07 \mathrm{~h}^{-1}$ foi assumido para o parâmetro taxa de degradação do concentrado (K2Concentrate).

Para calcular a quantidade de amido presente no carbohidrato não estrutural (NSC), o conteúdo de amido do farelo de arroz, sorgo e milho foi considerado de $90 \%$ do NSC (NRC, 1996). O conteúdo de amido em resíduos foi considerado como $50 \%$ de NSC, porque o resíduo era resultante de uma mistura de sementes, grãos quebrados e palha. Grãos e sementes possuem ao redor $90 \%$ de amido, enquanto que a palha contém somente $5 \%$ de amido no NSC ( NRC, 1996). Por isso, foi assumido que $65 \%$ do concentrado continha $90 \%$ de amido no NSC e o restante continha $50 \%$ de amido. Consequentemente, o modelo considerou que o suplemento continha $60.25 \%$ de amido no NSC. O valor para DCWConcentrate foi obtido do mesmo modo que DCWForage, como o citado anteriormente.

\section{SIMULAÇÕES}

Os dados de DIVMS da forragem nos diferentes períodos do ano obtidos no laboratório foram comparados com os simulados pelo modelo (Figura 3). ILLIUS \& GORDON (1991) e HERRERO (1997) validaram os sub-modelos de consumo e digestão utilizando dados disponíveis na literatura. Entretanto, modificações foram introduzidas principalmente na simulação do consumo animal conforme o descrito anteriormente.

A variação dos valores da digestibilidade da forragem (mínimo, médio e máximo) simulado pelo modelo (Figura 3), representa o comportamento dinâmico esperado na digestão da forragem pelo animal. Os dados são referentes à digestibilidade diária, no entanto, o tempo de permanência da forragem no rúmen varia com a qualidade da mesma, conseqüentemente, os padrões de digestibilidade das forragens estão correlacionados com estes fluxos de passagem (VAN SOEST, 1994). Os valores médios têm uma pequena diferença, quando comparados aos valores apresentados na tabela 1. Este fato decorre que os valores simulados representam a média dos valores por período, enquanto que na tabela 1 é apresentado o valor único obtido no laboratório. Outra possível razão a influenciar as diferenças verificadas foi a dieta alimentar a que os animais estavam submetidos (suplementação com concentrado). O modelo simula que o aumento no nível alimentar aumenta a taxa de passagem, reduzindo conseqüentemente, a digestibilidade do alimento. Em contraste, principalmente dentro do período de 29/07 para 20/10, quando a qualidade da pastagem (Tabela 1) era baixa, a melhora do ambiente do rúmen através do concentrado aumenta a digestibilidade da forragem. Estes resultados estão de acordo com aqueles descritos por CATON \& DHUYVETTER, (1996) de que o suplemento pode aumentar ou reduzir a digestibilidade da forragem, conforme a qualidade da mesma e a quantidade e qualidade do suplemento fornecido na dieta.

A comparação entre os resultados da simulação e os dados reais de ganho de peso dos animais é apresentada na figura 4. Foram feitas três

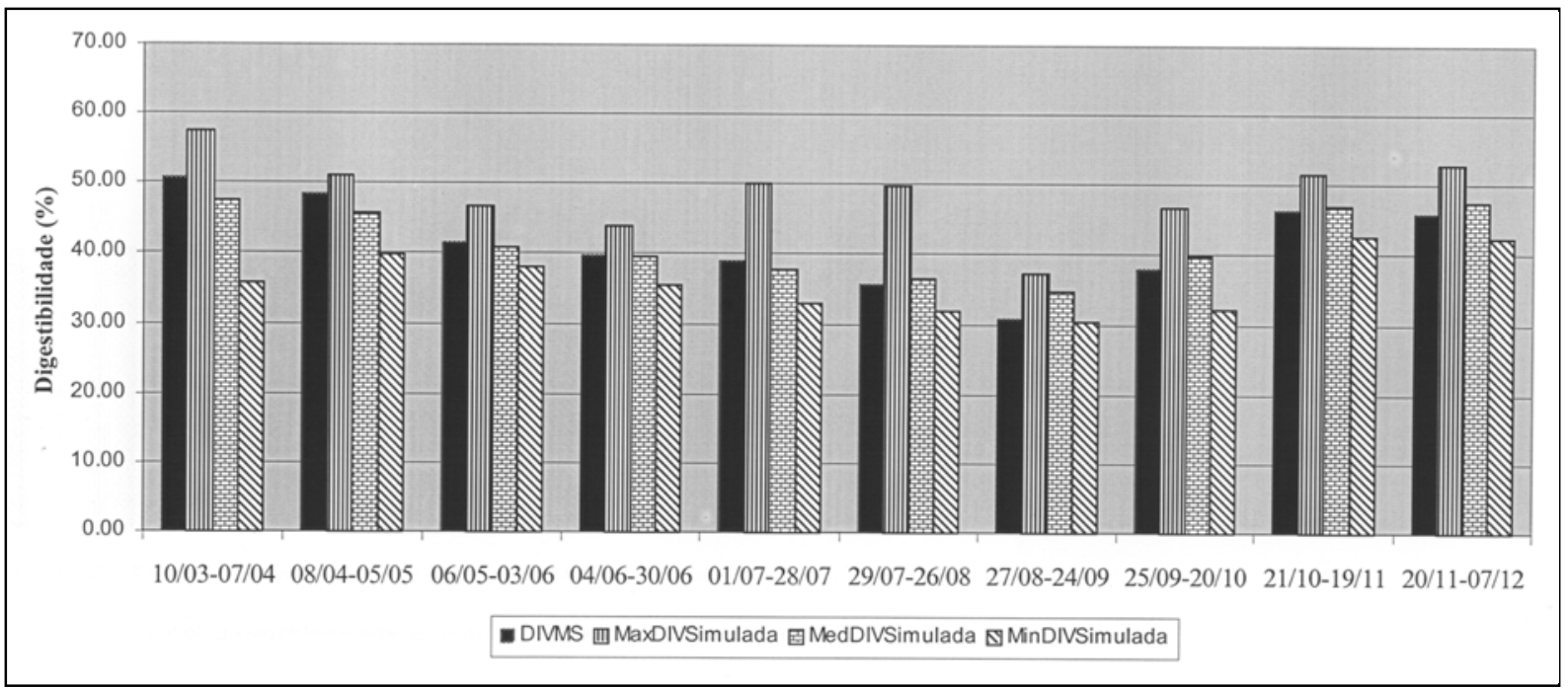

Figura 3 - Digestibilidade in vitro da MS obtida no laboratório (DIVMS) comparada com a digestibilidade máxima, mínima e média simulada pelo modelo para cada período do ano. 
a) Simulação do ganho de peso $(\mathrm{kg})$ sem considerar seleção de dieta

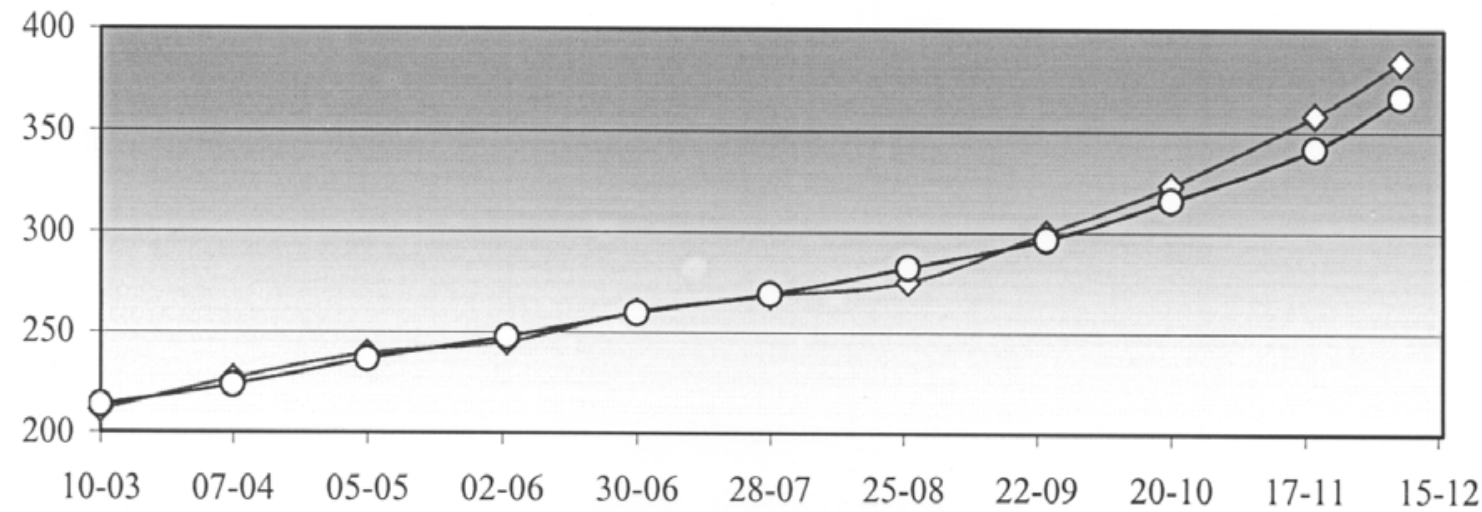

b) Simulação do ganho de peso $(\mathrm{kg})$ considerando $5 \%$ de seleção de dieta

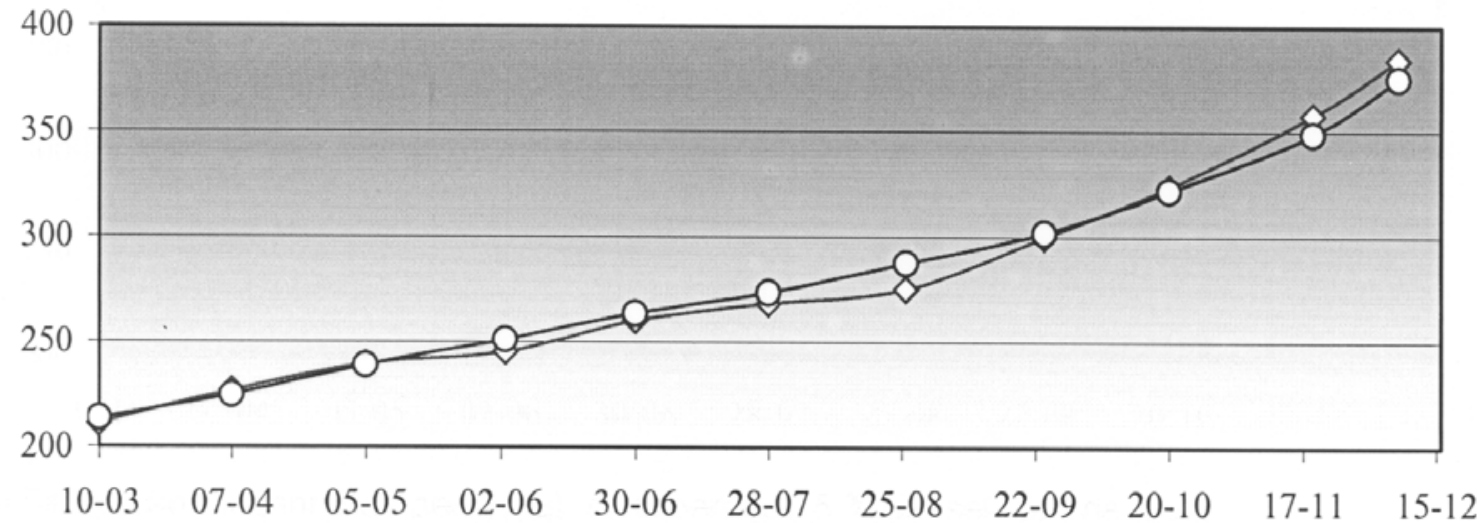

c) Simulação do ganho de peso $(\mathrm{kg})$ considerando 10 \% de seleção de dieta

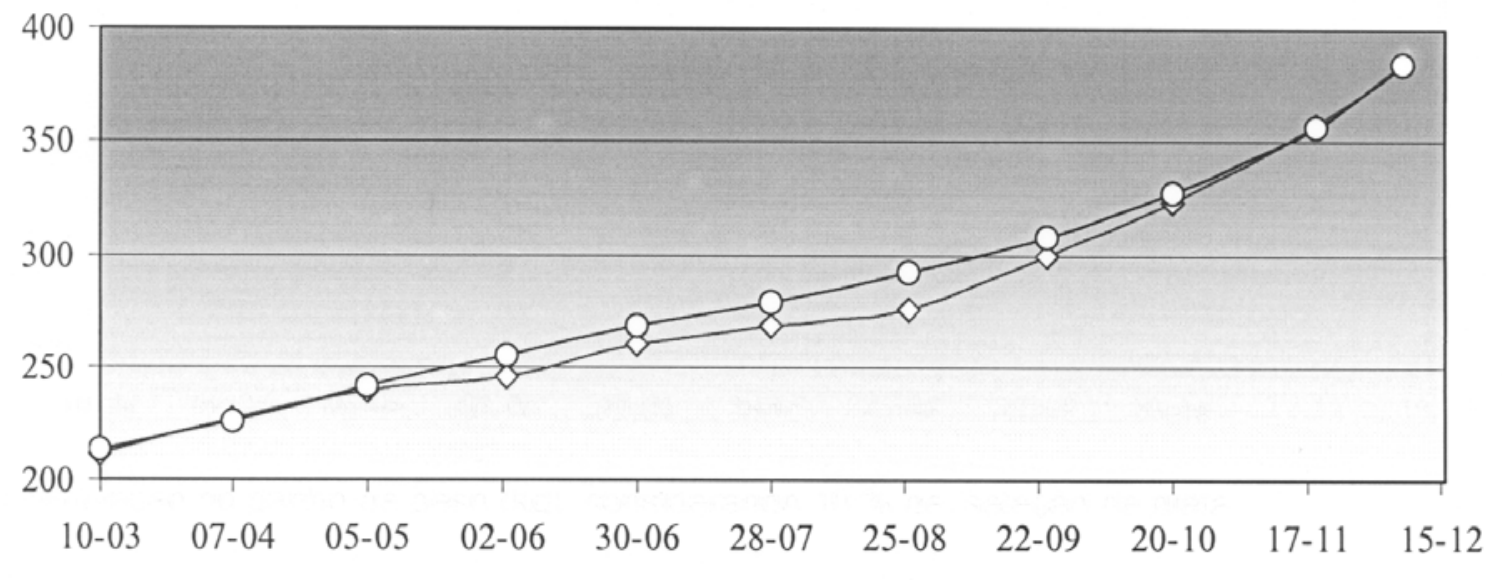

Figura 4 - Comparação do ganho de peso animal no experimento com o obtido por meio de simulação, considerando seletividade animal ( --৩-- Real, --o-- Simulado). 
simulações para comparar os dados reais com os dados simulados pelo modelo. A primeira simulação não considera a capacidade seletiva dos animais e os valores de qualidade da dieta, considerados como entradas no modelo, e fornecidos nas tabelas 1,2 e 3. As outras simulações consideram a capacidade de seleção do animal durante o pastoreio, com um incremento na qualidade da dieta, numa percentagem de cinco e dez por cento acima dos valores laboratoriais. $\mathrm{Na}$ figura $4 \mathrm{a}$, quando a seletividade animal não foi considerada, a curva de ganho de peso simulada pelo modelo apresenta uma boa concordância com os dados obtidos no campo. Porém, o ganho de peso dos animais durante a primavera foi mais rápido que o simulado pelo modelo. Um aumento de $5 \%$ na qualidade da dieta (Figura 4b) reduz esta diferença na primavera, mas uma pequena diferença no período de inverno pode ser percebida. Esta diferença é maior quando um aumento de $10 \%$ na qualidade de dieta é considerado (Figura 4c). Porém, a este nível de qualidade de dieta, a predição do peso vivo final tem um excelente performance. Simulações utilizando dados de animais submetidos a outros regimes alimentares é o próximo desafio para o modelo.

\section{CONCLUSÕES}

Os resultados simulados pelo PAMPA CORTE apresentaram uma boa performance na simulação do ganho de peso de machos mestiços Hereford X Nelore suplementados em campo nativo, principalmente, quando a seletividade animal foi considerada.

\section{REFERÊNCIAS BIBLIOGRÁFICAS}

ANDERSON, D.R., SWEENEY, D.J., WILLIANS, T.A. Introduction to statistics: concepts and applications. St. Paul : West, 1994. p.82-83.

AFRC. Energy and protein requirements of ruminants. Wallingford: CAB International, 1993. 159p.

ARC. The nutrient requirements of ruminant livestock. Slough, UK : Commonwealth Agricultural Bureaux, 1980. $351 \mathrm{p}$.

BECK, A.C., DENT, J.B. A farm growth model for policy analysis in an extensive pastoral production system. Australian Agricultural Economics Society, v.31, p.29-44, 1987.

CATON, J.S., DHUYVETTER, D.V. Influence of energy supplementation on grazing ruminants: requirements and responses. Journal of Animal Science, v.75, p.533-542, 1996.

CHUDLEIGH, P.D.; CEZAR, I.M. A review of bio-economic simulation models of beef production systems and sugestions for methodological development. Agricultural Systems, v.8, p.273-289, 1982.

COBLENTZ, W.K., FRITZ, J.O., FICK, W.H., et al. In situ dry matter, nitrogen, and fiber degradation of alfalfa, red clover, and Easter gamagrass at four maturities. Journal of Dairy Science, v.81, p.150-161, 1998.

CSIRO. Feeding standards for Australian livestock. Victoria: CSIRO, 1990. 266p.

DENT, J.B. Theory and practice in FSR/E: Consideration of the role of modelling. In: CIRAD-SAR. System-oriented research in agriculture and rural development. Montpellier : CIRAD-SAD, 1996. p.100-110.

DENT, J.B., Mc GREGOR, M.J., EDWARDS-JONES, G. Integrating livestock and socio-economic systems into complex models. In: GIBON, A., FLAMANT J.C. T he study of livestock farming systems in a research and development framework. Wageningen : Wageningen, 1994. p.25-36.

DENT, J.B., THORNTON, P.K. The role of biological simulation models in farming systems research. Agriculture administration and extension, v.29, p.111-122, 1988.

DE PETERS, E.J., FADEL, J.G., AROSEMENA, A. Digestion kinetics of neutral detergent fiber and chemical composition within some selected by-product feedstuffs. Animal Feed Science and Technology, v.67, p.127-140, 1997.

DOANE, P.H., SCHOFIELD, P., PELL, A.N. Neutral detergent fibre disappearance and gas and volatile fatty acid production during the in vitro fermentation of six forages. Journal of Animal Science, v.75, p.3342-3352, 1997.

GONÇALVES, M.B.F., SACCOL., A.G.F. Alimentação animal com resíduo de arroz. Santa Maria : Palloti, 1995. 77p.

HANSON J.D., PARTON W.J., INNIS G.S. Plant growth and production of grassland ecosystems: a comparison of modeling approaches. Ecological Modelling, v.29, p.131$144,1985$.

HERRERO, M. Modelling dairy grazing systems: an integrated approach. Edinburgh, UK, 1997. 360p. Thesis (PhD em Manejo de Recursos) - Institute of Ecology and Resouce Management, University of Edinburgh. 1998.

HERRERO, M., DENT, J.B., FAWCETT, R.H. The plant-animal interface in models of grazing systems. In: PEART R.M., CURRY R.B.. Agricultural systems modelling and simulation. New York : Marcel Dekker. 1998. p.495-542.

ILLIUS, A.W., GORDON, I.J. Prediction of intake and digestion in ruminants by a model of rumen kinetics integrating animal size and plant characteristics. Journal of Agricultural Science, v. 116, p.145-157, 1991.

ILLIUS, A.W., JESSOP, N.S. Metabolic constraints on voluntary intake in ruminants. Journal of Animal Science, v.74, p.3052-3062, 1996.

KRISHNAMOORTHY, U., SOLLER, H., STEINGASS, H., et al. Energy and protein evaluation of tropical feedstuffs for whole tract and ruminal digestion by chemical analyses and rumen inoculum studies in vitro. Animal Feed Science and Technology, v.52, p.177-188, 1995. 
MACNEIL M.D., SKILES J.W., HANSON J.D. Sensitivity analysis of a general rangeland model. Ecological Modelling, v.29, p.57-76, 1985.

MONTEITH, J.L. The quest for balance in crop modeling. Agronomy Journal, v.88, p.695-697, 1996.

NRC. Effect of environment on nutrients requirements of domestic animals. Washington : National Academy, 1981. $152 \mathrm{p}$.

NRC. Nutrient requirements of beef cattle. Washington : National Academy of Science. 1996. 242p.
SNIFFEN, C.J., O'CONNOR, J.D., VANSOEST, P.J., FOX, D.G., et $\boldsymbol{a l}$. A net carbohydrate and protein system for evaluating cattle diets: II. Carbohydrate and protein availability. Journal of Animal Science, v. 70, p.3562-3577, 1992.

SILVEIRA, V.C.P., TRINDADE, A. M. de SOUSA, et al. A integração socio-bio-econômica através de modelos matemático: uma aplicação de estudo na região sudoeste do estado do Rio Grande do Sul - Brasil. Bagé. EMBRAPA/CPPSUL, 2000. 29p. (Boletim de Pesquisa, 22).

VAN SOEST, P.J. Nutritional ecology of the ruminant. Ithaca: Cornell University, 1994. 476p. 